\title{
Motor Pathway Analysis in HAM/TSP Using Magnetic Stimulation and F-waves
}

\author{
Ronald E. Young, Owen St.C. Morgan and Allan Forster
}

\begin{abstract}
Background: Tropical Spastic Paraparesis/HTLV-I Associated Myelopathy (HAM/TSP) is a chronic, progressive myelopathy endemic to the Caribbean. In HAM/TSP, peripheral motor pathways have been assessed using electromyography and nerve conduction studies; central motor pathways have been assessed to a limited extent using electrocortical stimulation. We used magnetic cortical stimulation (a painless alternative to electrocortical stimulation) and F-wave analysis to study conduction in the central and peripheral motor pathways in 18 HTLV-I seropositive, Jamaican TSP patients (ages 2970 years; duration of symptoms 3-20 years) and 22 normal controls. Methods: Magnetic cortical stimulation was effected using a $9 \mathrm{~cm}$ diameter undamped MES10 coil. F-waves and M-responses were elicited by electrical stimulation of the ulnar nerve at the wrist, and deep peroneal stimulation at the knee. Stimulation and recording of response latencies in abductor digitii minimi (ADM) and tibialis anterior (TA) were carried out using a Cadwell Excel system. Results: With cortical stimulation, response latencies (TMCTs) to ADM and TA were prolonged in the patients relative to controls. F-wave and $\mathrm{M}$-response latencies were unaffected, suggesting no peripheral pathology. Latency (CMCT) between cortex and lumbar cord was significantly prolonged; that between cortex and C7/T1, also, but less markedly $(\mathrm{P}<0.0005)$. Amplitudes of cortically evoked responses were significantly reduced only in the lower limbs (TA). CMCT increased as the disease progressed from mild to moderate, thereafter remaining largely unchanged. Conclusions: Meta-analysis of interlaboratory control data revealed no significant differences in TMCTs between our controls and others studied using similar techniques. The observations are consistent with pathology affecting mainly the thoracolumbar cord in HAM/TSP.
\end{abstract}

RÉSUMÉ: Analyse des voies motrices dans la MAV/PST au moyen de la stimulation magnétique et des ondes F. Introduction: La myélopathie associée au VLTH/paraparésie spastique tropicale MAV/PST est une myélopathie progressive chronique endémique dans les Caraibes. Nous avons évalué les voies motrices périphériques dans la MAV/PST au moyen de l'électromyographie et d'études de la conduction nerveuse et, de façon plus limitée, les voies motrices centrales au moyen de la stimulation électrocorticale. Nous avons utilisé la stimulation magnétique corticale, une alternative indolore à la stimulation électrocorticale et l'analyse des ondes $F$ pour étudier la conduction dans les voies motrices centrales et périphériques chez 18 patients jamaïcains séropositifs pour le VLTH-1 atteints de PST, âgés de 29 à 70 ans et symptomatiques depuis 3 à 20 ans, et 22 sujets contrôles normaux. Méthodes: La stimulation corticale magnétique a été effectuée au moyen d'une inductance MES 10 non amortie de $9 \mathrm{~cm}$ de diamètre. Les ondes $\mathrm{F}$ et les réponses $\mathrm{M}$ étaient obtenues par stimulation électrique du nerf radial au poignet et du nerf tibial antérieur au genou. La stimulation et l'enregistrement des temps de latence dans l'abducteur du Ve doigt (AVD) et dans le jambier antérieur (JA) ont été effectués au moyen d'un système Cadwell Excel. Résultats: Avec la stimulation corticale, les temps de latence (TLSCs) de l'AVD et du JA étaient prolongés chez les patients. Les ondes F et les latences $M$ n'étaient pas atteintes, suggérant qu'il n'existait pas de pathologie périphérique. Le temps de latence entre le cortex et la moelle lombaire était significativement prolongé, de même qu'entre la cortex et C7/D1, mais beaucoup moins $(p<0.0005)$. L'amplitude des réponses évoquées corticales était significativement diminuée seulement aux membres inférieurs $(\mathrm{JA})$. Le temps de latence augmentait à mesure que la maladie progressait de légère à modérée et demeurait stable par la suite. Conclusions: Une méta-analyse de données contrôles interlaboratoires n'a pas révélé de différences significatives entre les TLSCs de nos contrôles et d'autres sujets étudiés par des techniques semblables. Ces observations sont compatibles avec une pathologie affectant surtout la moelle dorsolombaire dans la MAV/PST.

Can. J. Neurol. Sci. 1998; 25: 48-54

Tropical Spastic Paraparesis/HTLV-I Associated Myelopathy (HAM/TSP), a retroviral disease, is a chronic, progressive myelopathy endemic to Jamaica and other Caribbean islands, characterized by spasticity of the lower limbs, back pain, bladder and bowel dysfunction, and variable proprioceptive loss. Its clinical and pathological features have been
From the Departments of Basic Medical Sciences (R.E.Y.), Medicine (O.S.M.), Faculty of Medical Sciences, University of the West Indies, Mona, Jamaica; and Neurophysiology (A.F.), Dundee Royal Infirmary, Dundee, Scotland.

RECEIVED JANUARY 3, 1997. ACCEPTED IN FINAL FORM JULY 10, 1997.

Reprint requests to: Ronald E. Young, Department of Basic Medical Sciences, University of the West Indies, Mona, Kingston 7, Jamaica, West Indies. 
extensively reported. ${ }^{1.5}$ Electrophysiological assessment of central nervous system deficits in HAM/TSP has been mainly restricted to study using sensory evoked potentials. ${ }^{6-8}$ Motor pathways have been evaluated by transcranial electrical stimulation, ${ }^{9-11}$ to a limited extent, due to the accompanying pain and discomfort. ${ }^{12}$ Transcranial magnetic stimulation permits activation of the motor cortex through the intact cranium, without exciting superficial nociceptors, and is therefore painless. ${ }^{13} \mathrm{By}$ stimulating at different levels along the motor pathways, it is possible to quantify the integrity of both central and peripheral segments. Transcranial magnetic stimulation has been used to study central motor conduction time (CMCT) in multiple sclerosis, ${ }^{14}$ motor neurone disease, ${ }^{15}$ hereditary motor and sensory neuropathy, and hereditary spastic paraplegia. ${ }^{16}$

In the present study, we have used magnetic stimulation of the motor cortex to measure total motor conduction times (TMCT) to the upper and lower limbs in HTLV-I positive Jamaican patients with TSP. F-wave analysis was used to evaluate peripheral motor conduction times. This report summarizes our findings, and also carries out a meta-analysis on the results of studies on normal controls using similar techniques.

\section{Patients and Methods}

\section{Patients and Controls}

The group tested consisted of 18 Jamaican HAM/TSP patients, 16 females and 2 males, aged 29-70 years (mean 51 years). The illness varied in severity from mild weakness to paralysis, and in duration from 3-20 years. Patients included in the study fulfilled the criteria of the WHO diagnostic guidelines for HAM/TSP. ${ }^{17}$ The control group consisted of 22 healthy volunteers, 9 females and 13 males, aged 21-66 (mean 38 years). Subjects with a history of neurological disease other than TSP (patients), convulsive seizures or cardiac disease were excluded from the study. The technique was explained and demonstrated to all subjects and consent was obtained prior to the procedure.

\section{Protocol}

With the subject comfortably seated or supine, $\mathrm{Ag} / \mathrm{AgCl}$ electrodes were affixed over the belly and tendon of the abductor digiti minimi (ADM) and the tibialis anterior (TA) muscles, to record electromyographic (EMG) responses. Impedance was kept to $<10 \mathrm{kOhm}$.

A Cadwell MES10 magnetic stimulator was used to excite the motor cortex via an undamped $9 \mathrm{~cm}$ coil. The coil was placed tangentially over the vertex for upper limb studies, and was centered on the midline $5 \mathrm{~cm}$ in front of the vertex, for evoking lower limb responses. Anti-clockwise current in the coil was preferred for stimulating the right side and clockwise for the left ${ }^{18,19}$ although for the undamped MES10 coil, with suprathreshold currents, there was no noticeable difference. Cortical facilitation was produced by gentle voluntary contraction of the test muscles at about 5-10\% maximal force during stimulation. ${ }^{20}$ Total motor conduction times (TMCT) from cortex to muscle were obtained from these records.

For F-wave analysis, distal nerves were stimulated by conventional percutaneous electrical pulses - the ulnar nerve at the wrist, and the deep peroneal nerve at the knee, with the cathode placed proximal to the anode. Stimulus strength was increased until a maximal motor response was obtained, then ten successive responses were recorded. The shortest $F$-wave and $M$-wave latencies ( $F$ and $M$ respectively), as well as the maximal amplitude of the M-response, were measured. Peripheral motor conduction time (PMCT) from motor axon origin to muscle (ADM or TA) was derived as $(\mathrm{F}+\mathrm{M}-1) / 2,1 \mathrm{~ms}$ being the estimated central delay time. ${ }^{21}$ PMCT derived in this way was designated as $\mathrm{PMCT}_{U}$ for the upper limb, and as $\mathrm{PMCT}_{\mathrm{L}}$ for the lower limb. This estimate of PMCT would include conduction along the most proximal segments of the motor axons, thus permitting a theoretically more accurate, and usually higher, estimate of PMCT than radicular stimulation, using either magnetic or electrical pulses.

A Cadwell Excel system (Cadwell Laboratories, Inc., 909 North Kellogg St., Kennewick, Washington 99336, USA) controlled the delivery of electrical and magnetic stimuli, amplification and filtering (band-width $10 \mathrm{~Hz}$ to $5 \mathrm{kHz}$ ), recording and display of electromyographic waveforms, and determination of latencies to onset, and amplitudes from baseline to negative peak. the highest amplitude and shortest latency of four consistent responses were recorded. Latencies were determined at an amplification of $100 \mu \mathrm{V} /$ division on the display screen. Limb temperature in the laboratory ranged from 33 to $35^{\circ} \mathrm{C}$, a range within which there is little influence on conduction velocities. ${ }^{21,22}$ Arm length (C7 to wrist) and standing height were routinely recorded for all subjects.

\section{Data Processing}

All data were entered on pre-coded forms and transferred in to a LOTUS 123 spreadsheet for further processing and graphical display. Central motor conduction time (CMCT) for upper and lower limbs respectively, was derived by subtracting PMCT obtained by F-wave analysis, from the TMCT. In order to eliminate the effects of individual variations in muscle mass, subcutaneous fat, etc., amplitudes of the cortically induced responses were expressed as a percentage of the maximal M-response amplitudes. Severity of the disease was rated at 1 for patients who were ambulant without great difficulty or need for assistance; 2 for patients who had markedly impaired gait or needed assistance; and 3 for patients who were confined to a wheelchair. Statistical analysis of the results was carried out using the multivariate linear regression module in SYSTAT. ${ }^{23.24}$ Variables were adequately normalized using logarithmic transformation where necessary. The regression model used was:

$$
\mathrm{Y}=\text { Constant }+ \text { Group + Age + Height }+ \text { Side }
$$

where Group (patients vs. controls) and Side (right/left) were categorical variables. The first order interaction terms (age* group, height*group, side* group) were checked for significance and then removed from the regression model if and when they were found to be insignificant.

\section{RESULTS}

The salient features of the study groups are listed in Table 1. Eight of the patients were only mildly disabled, four used a cane or Zimmer frame and six were wheelchair-bound. The electrophysiological findings are summarized in Tables 2 and 3 . Within both patient and control groups, height tended to be a much more significant determinant than age, for both latencies and amplitudes. In 
Table 1: Clinical Features of TSP Patients and Normal Controls.

\begin{tabular}{lcl}
\hline Variable & Patients & Controls \\
\hline Mean Age (range) y & $51(29-70)$ & $38(21-66)$ \\
Mean Height (range) cm & $162(152-172)$ & $170(152-185)$ \\
$\mathrm{N}$ & 18 & 22 \\
Males/Females & $2 / 16$ & $13 / 9$ \\
Duration of Illness & & \\
$\quad$ Mean (range) y & $8.1(3-20)$ & - \\
Clinical status & Mild weakness & No neurological or \\
& to complete paralysis & cardiac disorders \\
\hline
\end{tabular}

both groups the cortically evoked EMG responses were smaller than those evoked by distal, electrical, motor nerve stimulation (M-responses). There was no significant increase in absolute differences between right and left side latencies or amplitudes, among TSP patients relative to controls, indicating that in general, the disease tended to affect the pathways symmetrically, causing no increase in right/left differences.

\section{Response Amplitudes in Patients and Controls}

Amplitudes of the $\mathrm{M}$-responses in the ADM in patients and controls were not significantly different (Table 2). Amplitudes of EMG responses obtained from the ADM by magnetic stimulation of the motor cortex, and expressed as a percentage of the M-response amplitudes, (Ctx/Wrist)\%, averaged about $44 \%$ for controls and $33 \%$ in patients (Table 2). The difference was not significant. These amplitudes were not normally distributed and are therefore expressed as medians and ranges.

Differences between controls and patients were more pronounced for the lower limbs. Amplitudes (Table 2) for the $\mathbf{M}$ response in TA were significantly reduced in the patients. In addition, amplitudes of the cortically evoked EMGs, expressed as a percentage of the $\mathrm{M}$-response amplitude, (Ctx/Knee)\%,

Table 2: Amplitudes of EMG Responses in TSP Patients and Controls. The distribution of the values often deviated markedly from normality. In TSP patients, upper limb EMGs were reduced, but not significantly so, in response to cortical and stimulation only; lower limb EMGs were significantly reduced in response to both cortical and peripheral nerve stimulation.

\begin{tabular}{|c|c|c|c|c|c|}
\hline EMG & $\begin{array}{l}\text { No. } \\
\text { Sides }\end{array}$ & $\begin{array}{l}\text { Controls } \\
\text { median (mean) } \\
\text { [range] } m V\end{array}$ & $\begin{array}{l}\text { No. } \\
\text { Sides }\end{array}$ & $\begin{array}{l}\text { Patients } \\
\text { median (mean) } \\
\text { [range] } m V\end{array}$ & $\begin{array}{l}\mathbf{P} \\
*=\text { Sig. }\end{array}$ \\
\hline \multicolumn{6}{|l|}{ Upper Limbs } \\
\hline $\begin{array}{l}\text { 1. M-response } \\
\text { Wrist } \rightarrow(A D M)\end{array}$ & 43 & $\begin{array}{l}7.5(7.8) \\
{[3.4-13.01]}\end{array}$ & 27 & $\begin{array}{l}7.6(7.5) \\
{[2.0-12.4]}\end{array}$ & 0.201 \\
\hline 2. $(\mathrm{Ctx} / \mathrm{Wrist}) \% \dagger$ & 43 & $\begin{array}{l}42.8(43.8) \% \\
{[13.0-89.7 \%]}\end{array}$ & 27 & $\begin{array}{l}28.5(33.1) \% \\
{[6.0-101 \%]}\end{array}$ & 0.157 \\
\hline \multicolumn{6}{|l|}{ Lower Limbs } \\
\hline $\begin{array}{l}\text { 3. M-response } \\
(\text { Knee } \rightarrow \mathrm{TA})\end{array}$ & 42 & $\begin{array}{l}5.3(5.5) \\
{[2.0-9.8]}\end{array}$ & 26 & $\begin{array}{l}4.5(4.7) \\
{[3.1-8.6]}\end{array}$ & $0.010^{*}$ \\
\hline 4. $(\mathrm{Ctx} / \mathrm{Knee}) \% \dagger$ & 39 & $\begin{array}{l}36.0(37.6) \% \\
{[0.88-95.3 \%]}\end{array}$ & 26 & $\begin{array}{l}5.6(6.6) \% \\
{[2.4-19.7 \%]}\end{array}$ & $<0.0005^{*}$ \\
\hline
\end{tabular}

$\nmid$ Ratio of amplitude of cortically evoked EMG, to M-response amplitude.
Table 3: Response Latencies in Patients and Controls. Latencies have been adjusted for age and height. Total motor conduction time (TMCT) for both upper and lower limbs is prolonged in the patient group. For upper and lower limbs, M-response latency, and peripheral motor conduction time (PMCT) computed by F-wave latency, are unaffected.

\begin{tabular}{lccccc}
\hline Latency & No. & Controls & No. & Patients & $\begin{array}{c}P \\
m s\end{array}$ \\
Sides & $\pm S D m s$ & Sides & $\pm S D m s$ & $*=S i g$. \\
\hline
\end{tabular}

\section{Upper Limbs}

$\begin{array}{llllll}\text { 1. } \mathrm{TMCT}_{\mathrm{U}} & 43 & 19.8 \pm 1.23 & 36 & 21.8 \pm 1.94<0.0005^{*} \\ \text { 2. } \mathrm{PMCT}_{U}^{\dagger} & 43 & 14.4 \pm 1.02 & 27 & 14.3 \pm 0.96 & 0.872 \\ \text { 3. } \mathrm{Wrist}_{\mathrm{ADMM}} \mathrm{ADM} & 43 & 2.70 \pm 0.45 & 28 & 2.83 \pm 0.46 & 0.343 \\ \text { 4. } \mathrm{CMCT}_{\mathrm{U}^{\ddagger}} & 43 & 5.43 \pm 1.00 & 27 & 7.63 \pm 2.13<0.0005^{*}\end{array}$

Lower Limbs

$\begin{array}{llllll}\text { 5. } \mathrm{TMCT}_{\mathrm{L}} & 42 & 26.6 \pm 2.39 & 35 & 36.1 \pm 5.76 & <0.0005^{*} \\ \text { 6. } \mathrm{PMCT}_{\mathrm{L}} \dagger & 42 & 16.6 \pm 1.14 & 26 & 16.6 \pm 1.14 & 0.939 \\ \text { 7. } \mathrm{Knee} \rightarrow \mathrm{TA} & 42 & 3.25 \pm 0.55 & 26 & 3.08 \pm 0.49 & 0.249 \\ \text { 8. } \mathrm{CMCT}_{\mathrm{L}} \ddagger & 40 & 10.3 \pm 2.52 & 25 & 20.2 \pm 5.33<0.0005^{*}\end{array}$

$\dagger \mathrm{PMCT}$ was computed as $(\mathrm{F}+\mathrm{M}-\mathrm{I}) / 2$, where $\mathrm{F}=\mathrm{F}$-wave latency; $\mathrm{M}=\mathrm{M}$ response latency, and $1 \mathrm{~ms}=$ estimated central delay time. ${ }^{21}$ $\ddagger$ СMCT obtained by subtracting PMCT from TMCT.

were also significantly reduced from $38 \%$ in controls to $7 \%$ in patients.

\section{Latencies in Patients and Controls}

Response latencies in the control group (Table 3) for Cortex $\rightarrow$ ADM $\left(\mathrm{TMCT}_{\mathrm{U}}\right)$ and for Cortex $\rightarrow$ TA $\left(\mathrm{TMCT}_{\mathrm{L}}\right)$, as well as for Wrist $\rightarrow$ ADM and for Wrist/ADM F-waves, were similar to previously published values (see Discussion). Comparable latencies for Knee $\rightarrow$ TA M-responses, and for Knee/TA F-waves, were unavailable.

Latencies for M-responses were not significantly different between patients and controls, either in upper or in lower limbs (Table 3). PMCT also showed no significant differences between groups, for either upper or lower limbs; nor did conduction velocities computed using F-wave latencies for the upper limbs. (Controls: $62.9 \pm 3.4 \mathrm{~m} / \mathrm{sec}$; Patients: $61.4 \pm 3.0$ $\mathrm{m} / \mathrm{sec} ; \mathrm{P}=0.14$ ). Our data did not allow us to estimate conduction velocities for the lower limbs.

Total motor conduction times (TMCT) for cortically-induced responses were significantly prolonged $(\mathrm{P}<0.0005)$ among the TSP patients, by $10 \%$ and $30 \%$ respectively, in the upper and lower limbs. $\mathrm{CMCT}_{U}$ and $\mathrm{CMCT}_{\mathrm{L}}$, computed as the difference between TMCT and PMCT for upper and lower limbs respectively, were $41 \%$ and $96 \%$ longer, in patients than in controls ( $P$ $<0.0005$ ).

CMCT for upper and lower limbs, is plotted against amplitude of the cortically evoked responses, expressed as a percentage of M-response amplitude, for both patients and controls, in Figure 1. For the lower limbs, the use of amplitude and central latency measurements jointly afforded a clear separation between patient and control populations. Differences for the upper limbs were not as clear-cut, in spite of the fact that the clinically spared upper limbs did show significant deficits in latencies and amplitudes. In neither case does amplitude help greatly in improving the separation between patients and controls. 


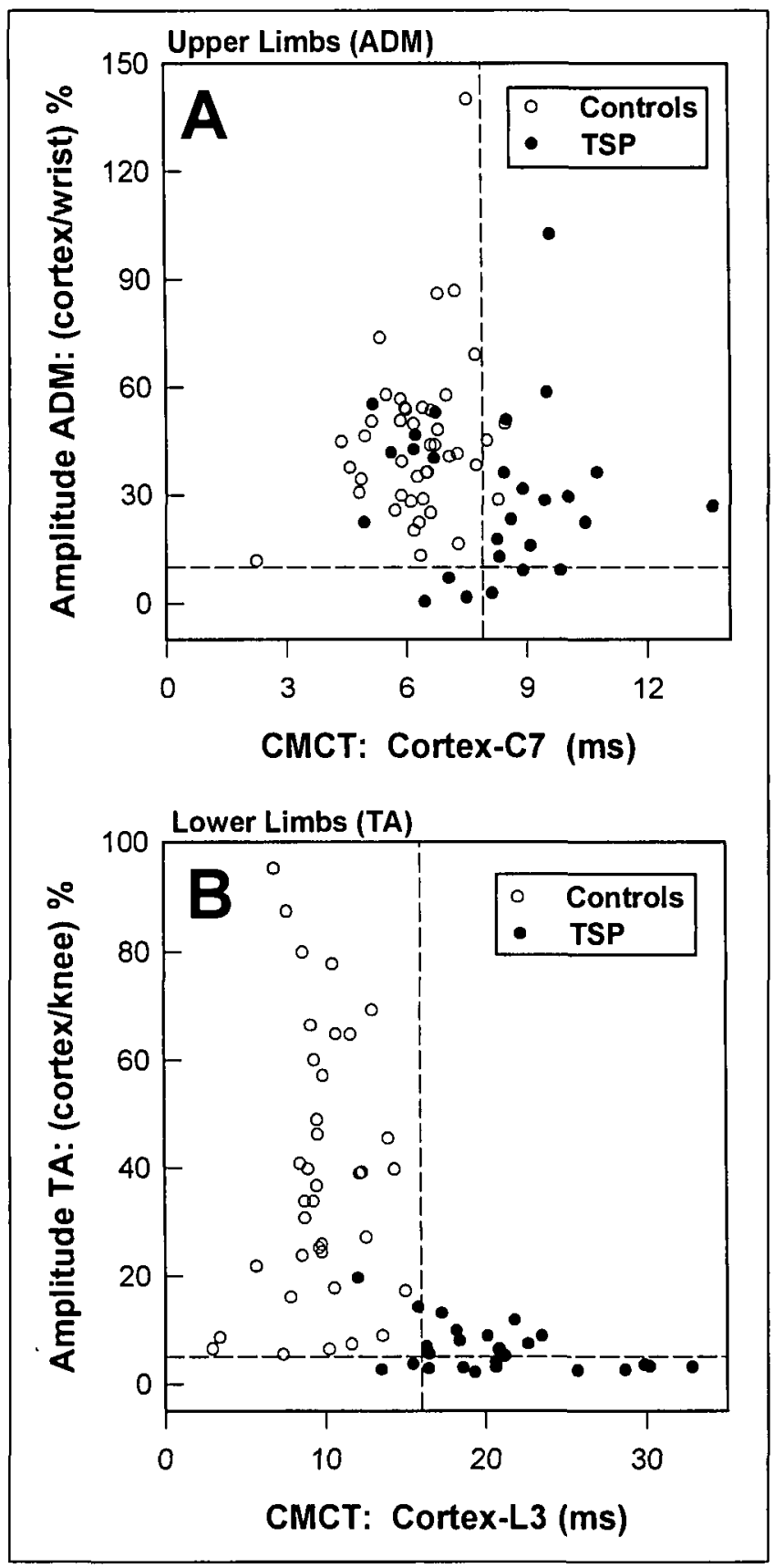

Figure 1: The combination of response amplitude and the central motor conduction times (CMCT) for upper $(A)$, and for lower limbs $(B)$, allows clear differentiation of HAMITSP patients from controls. These variables allow the best overall discrimination between TSP patients and controls. In the case of the upper limbs, amplitude adds little to the discrimination, but for the lower limb responses, it contributes significantly, though only slightly. Amplitudes of cortically evoked muscle action potentials are expressed as a percentage of the amplitude of the response to distal stimulation of the peripheral nerve ( $M$-response). Vertical lines on the plots indicate means plus 2.5 SD for latencies of control subjects. Horizontal lines indicate antilogs of the mean minus 2.5 $S D$, of the log-transformed amplitudes for healthy controls.

For both upper and lower limbs, CMCT was significantly longer in patients with moderate as compared with mild disease (Figure 2), but showed no significant difference between moderate and severe cases. The trend was significant only for $\mathrm{CMCT}_{\mathrm{U}}$

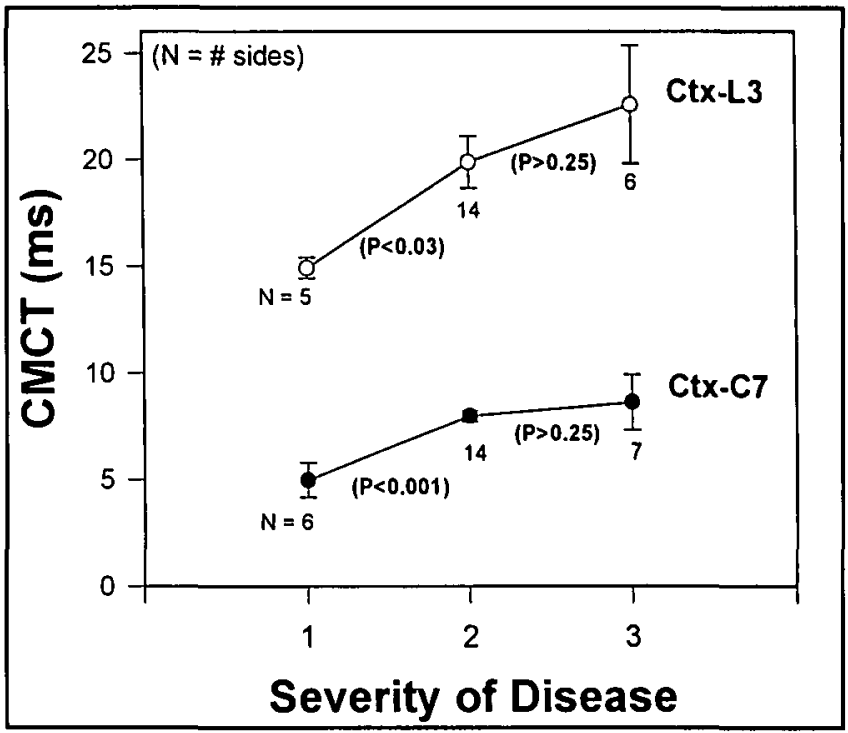

Figure 2: CMCT is significantly prolonged between the mild and the moderate cases, with little change between the moderate and severe. The overall trend is significant $(P<0.01)$ for $C M C T_{u}$ but not for $C_{M C T_{L}}(P<0.15)$. Beyond a critical degree of slowing, total block probably removes potentially slower fibres from the picture. This suggests that, in general, prolongation of latency is greatest in the early stages; and that once the patients come for clinical treatment, progressive latency increase is most evident in the less severely affected, cortico-cervical pathway. The later stages of the disease are probably associated more with fibre loss than with slowing of transmission in the descending pathways.

$(P=0.011)$. No measures were significantly correlated with the duration of symptoms.

\section{Discussion}

In this study, we evaluated the pathophysiology of conduction in the motor pathways from cerebral cortex, along the spinal cord and peripheral nerves, to distal muscles of the upper and lower limbs. The techniques employed were magnetic transcranial cortical excitation, and electrical peripheral nerve stimulation. In the control group the results were generally clear and reproducible, but it was sometimes difficult to elicit stable responses of easily detectable size in the TSP group. In order to establish the validity of our techniques, and to place potential comparisons in context, we compared our control results with those obtained using similar techniques, in other laboratories.

\section{Interlaboratory Comparisons of Control Latencies}

In Table 4, total motor conduction time for upper limbs of controls in the present study (TMCT ${ }_{u}$ ) are compared with the grand means derived from the results of five studies which used magnetic stimuli to elicit cortically facilitated muscle responses. ${ }^{25-29}$ The grand mean latency for $\mathrm{TMCT}_{\mathrm{U}}$ obtained by electrical cortical stimulation (facilitated) in nine studies was similar. ${ }^{9,18,20,29-34}$ For the lower limbs fewer comparable literature values were available. Total motor conduction time $\mathrm{TMCT}_{\mathrm{L}}$ in the present study approximated that obtained in one study using similar techniques, ${ }^{28}$ while the grand mean for TMCT $_{1}$ in five studies using electrical cortical stimulation (facilitated) was similar (Table 4). ${ }^{9,11,18,33,34}$ 
Table 4: Comparisons of total motor conduction times (TMCT) for present control group with those for other studies using magnetic and electrical cortical stimulation $( \pm S D$ ). The subscripts $U$ and $L$ refer to upper and lower limbs respectively.

\begin{tabular}{lll}
\hline Stimulus & \multicolumn{1}{c}{ TMCT $_{\mathbf{U}}$ ms } & TMCT $_{\mathbf{L}}$ ms \\
\hline $\begin{array}{l}\text { Present Study } \\
\text { Magnetic cortical } 19.8 \pm 1.2(\mathrm{n}=22)\end{array}$ & $26.6 \pm 2.4(\mathrm{n}=22)$ \\
& \\
$\begin{array}{l}\text { Other Studies } \\
\text { Magnetic cortical }\end{array}$ & $20.1 \pm 1.5(\mathrm{n}=117)^{25-29}$ & $27.4 \pm 1.2(\mathrm{n}=10)^{28}$ \\
& Range: $19.6-20.8$ & \\
Electrical cortical & $19.2 \pm 1.2(\mathrm{n}=155)^{9,18,20,29-34}$ & $27.6 \pm 1.5(\mathrm{n}=57)^{9.11 .18,33,34}$ \\
& Range: $18.3-20.3$ & Range: $26.2-29.3$ \\
\hline
\end{tabular}

Central motor conduction times to the upper and lower limb motor nuclei in the present controls, are compared with the corresponding grand mean latencies from other studies in Table 5. $\mathrm{CMCT}_{U}$ for the present controls, was similar to the value reported in one comparable study (Table 5). ${ }^{29}$ Another similar study reported a median of $5.6 \mathrm{~ms}$ (sides $=125$ ) ${ }^{35}$ Our mean F-wave conduction velocity for the upper limbs $(62.9 \pm 3.4 \mathrm{~m} / \mathrm{sec})$ was identical to the value of $62.9 \pm 4.6 \mathrm{~m} / \mathrm{sec}$ determined by Arimura et al. ${ }^{36}$ for their controls. No comparable studies were found which used $\mathrm{F}$-wave analysis to compute CMCT for the lower limbs. $\mathrm{CMCT}_{\mathrm{L}}$ obtained using magnetic stimulation of both cortex and nerve roots ${ }^{28}$ was $4.7 \mathrm{~ms}$ or $46 \%$ longer than our value; $\mathrm{CMCT}_{\mathrm{U}}$ was $2.1 \mathrm{~ms}$ or $39 \%$ longer (Table 5).

These comparisons, show that our control results agree substantially with those derived using similar techniques, in other laboratories. There is no significant difference between results obtained for TMCT using electrical or magnetic cortical stimulation with facilitation (Table 4). The meta-analysis for CMCT in Table 5, however, validates the expectation that F-wave analysis, should tend to yield longer PMCTs than magnetic root stimulation. This results in a prolongation of $\mathrm{CMCT}_{U}$ values obtained by magnetic cortical and magnetic root stimulation, compared to those determined by magnetic cortical stimulation and $\mathrm{F}$-wave wave analysis (Table 5).

\section{Response Amplitudes in HAM/TSP}

In 10 TSP patients Arimura et al. ${ }^{36}$ found no reduction in

Table 5: Comparisons of central motor conduction times (CMCT) for present control group with those for other studies using similar stimulation techniques.

\begin{tabular}{lll}
\hline $\begin{array}{l}\text { Stimulus } \\
\text { Configuration }\end{array}$ & CMCT $_{\mathbf{U}}(\mathrm{ms})$ & $\mathrm{CMCT}_{\mathbf{L}}(\mathrm{ms})$ \\
\hline $\begin{array}{l}\text { Present Study } \\
\text { Magnetic cortical/ } \\
\quad \text { F-wave analysis }\end{array}$ & $5.4 \pm 1.0(\mathrm{n}=22)$ & $10.3 \pm 2.5(\mathrm{n}=22)$ \\
$\begin{array}{l}\text { Other Studies } \\
\text { Magnetic cortical/ } \\
\quad \text { F-wave analysis }\end{array}$ & $5.8 \pm 1.1(\mathrm{n}=42)^{29}$ & - \\
$\begin{array}{l}\text { Magnetic cortical/ } \\
\text { Magnetic root }\end{array}$ & $7.5 \pm 1.1(\mathrm{n}=37)^{25.28}$ & $15.0 \pm 1.5(\mathrm{n}=10)^{28}$ \\
& Range: $7.4-7.9$ & \\
\hline
\end{tabular}

motor action potential amplitudes in response to peripheral nerve stimulation, in either upper or lower limbs. In the present study, amplitudes of EMG responses in the upper limb, to cortical and distal nerve stimulation also were unaltered, suggesting no significant loss of muscle mass, or degeneration in the central or peripheral pathways. However, the significant reduction in M-response amplitude in the lower limbs of the present TSP patients, could result either from disuse wasting, or atrophy consequent to motoneuron loss. The latter would be consistent with evidence of chronic partial denervation and muscle inflammation in HTLV-I associated myelopathy (HAM/TSP) ${ }^{36,37}$ Moreover, the amplitude of the cortically evoked response in TA is also significantly reduced in patients, even though it is expressed as a percentage of the distally evoked response. This suggests an impairment of the central pathways activating the motoneurones, in addition to the peripheral deficits. In spite of this, as noted previously, amplitude does not contribute greatly to the functional separation between patients and controls (Figure 1).

\section{Peripheral Latencies in HAM/TSP}

In three TSP patients, Hugon et al. ${ }^{10}$ found no change in PMCT in upper or lower limbs, in response to electrical stimulation at $\mathrm{C} 6 / \mathrm{C} 7$ and $\mathrm{T} 12 / \mathrm{Ll}$ respectively (means $=15.1$ and $16.7 \mathrm{~ms}$ respectively). Arimura et al. ${ }^{36}$ inferred a mild degree of involvement of proximal axons of lower-limb anterior horn cells, based upon slowing of F-wave conduction velocity in the tibial nerve (median nerve: $60.3 \pm 4.2$; tibial: $48.6 \pm 4.3$ $\mathrm{m} / \mathrm{sec}$ ), while conduction velocity in the more peripheral nerves was unaltered. In the present study neither M-response nor F-wave latencies was altered in the TSP group. The possible causes for these differences are unclear. The present findings, however, indicate no significant pathology in proximal segments of the motor roots or in peripheral nerves of TSP patients.

\section{Central Latencies in Patients and Controls}

In a study on three TSP patients, using transcranial and transcutaneous electrical stimulation, Hugon et al. ${ }^{10}$ found that $\mathrm{TMCT}_{U}$ (to ADM) was clearly but slightly prolonged in two, while $\mathrm{TMCT}_{\mathrm{L}}$ (to TA) and $\mathrm{CMCT}_{\mathrm{L}}$ were profoundly increased in all three. $\mathrm{CMCT}_{\mathrm{U}}$ was prolonged in one, normal in one and unobtainable in the third. Tomita et al., " using a similar technique in 8 patients with TSP, found $\mathrm{CMCT}_{\mathrm{U}}$ to be not significantly increased $(8.32 \pm 1.73 \mathrm{~ms})$, while $\mathrm{CMCT}_{\mathrm{L}}$ was markedly and significantly prolonged $(23.15 \pm 3.88 ; \mathrm{P}<0.01)$.

The small $(10 \%)$ but highly significant $(\mathrm{P}<0.0005)$ prolongation of $\mathrm{TMCT}_{\mathrm{U}}$ in the present study, indicates discernible upper limb pathology, with minimal clinical compromise, in HAM/TSP. This is due to mild slowing in the central, cortico-cervical pathway, with sparing of the peripheral nerves. The more pronounced slowing $(73 \%)$ of $\mathrm{TMCT}_{\mathrm{L}}$ is as expected, with CMCT being significantly prolonged by $46 \%$ and $96 \%$ respectively, in upper and lower limbs. The combined pattern could simply be a consequence of the longer axonal lengths in the cortico-lumbar as compared to the the cortico-cervical tracts, and the increased probability for the incidence of multiple sites of demyelination in the longer axons. However, it could also be in keeping with a picture of extensive demyelination at the level of the thoracic region of the cord, with milder effects in the cervical region. ${ }^{38}$ 
There is marked slowing of CMCT for both upper and lower limbs on transition from mild to moderate stages of the disease, but little further deterioration with progression from moderate to severe. This suggests that fibres slowed beyond a critical point may become totally blocked or degenerate, and so no longer contribute to the response pattern. Thus, transition from moderate to severe stages of the disease may be accompanied more by fibre loss than by slowing, in the descending pathways. The absence of significant correlations with duration of symptoms is in keeping with the known, uneven rate of progress of the disease in different patients. ${ }^{4}$

In conclusion, the results indicate that in TSP, significant conduction deficits can be found in both the cortico-cervical and cortico-lumbar motor pathways, but not in the peripheral nerves. F-wave and $\mathrm{M}$-response latencies are unaffected in both upper and lower limbs of our subjects. The observations emphasize the fact that the major pathologic changes are in the thoracolumbar cord, that the upper pathways are involved to a lesser extent, and the peripheral nerves are largely spared. Combined use of both EMG amplitude and central latency in response to magnetic cortical stimulation allows clear separation of HAM/TSP patients from healthy controls. The technique appears to be sufficiently sensitive to detect mild or sub-clinical upper limb deficits, and may provide a useful tool to discern early signs of TSP in HTLV-I seropositive patients, at a stage when treatment of these patients is likely to be effective, and when factors predisposing to the development of TSP might be more amenable to study.

\section{ACKNOWLEDGEMENTS}

We thank Roger McKechnie and Heather Stewart who offered valuable assistance during the conduct of the study.

\section{ReFERENCES}

I. Montgomery RD, Cruickshank EK, Robertson WB, McMenemey WH. Clinical and pathological observations on Jamaican neuropathy: a report on 206 cases. Brain 1964; 87: 425-462.

2. Morgan OStC, Montgommery RD, Rodgers-Johnson P. The myeloneuropathies of Jamaica: an unfolding story. QJ Med 1988; 67(252): 273-281.

3. Iwasaki Y. Neuropathology of HAM/TSP in Japan. Proceedings of the First Workshop on Neuropathology of Retrovirus Infections, Tokyo, 1989 (Aug 31).

4. Morgan OStC. Tropical spastic paraparesis: clinical features. In: Blattner WG, ed. Human Retrovirology: HTLV, NY, Raven Press Ltd., 1990: 199-204.

5. Morgan OStC, Barton EN. Jamaican neuropathy revisited. West Indian Med J 1993; 42: 138-141.

6. Shibasaki H. Notes on the pathophysiology of HTLV-I-associated myelopathy based on clinical and electrophysiological observations. In: Roman G, Vernant JC, Osame M, eds. HTLV-I and the Nervous System. New York: Alan R. Liss Inc., 1989: 227-232.

7. Castillo JL, Cartier L, Araya F, Verdugo R, Gibbs C. Evoked potential abnormalities in progressive spastic paraparesis. Acta Neurol Scand 1991; 83: 15I-154.

8. Eardley I, Fowler CJ, Nagendran K, Kirby RS, Rudge P. The neurology of tropical spastic paraparesis. Br J Urol 1991; 68: 589603.

9. Hugon J, Lubeau M, Tabaraud F, et al. Central motor conduction in motor neuron disease. Ann Neurol 1987; 22: 544-546.

10. Hugon J, Giordano C, Dumas M, et al. Evoked motor potentials in patients with tropical spastic paraplegia. In: Roman G, Vernant JC, Osame M, eds. HTLV-I and the Nervous System. New York: Alan R. Liss Inc., 1989: 233-238.
11. Tomita I, Motomura M, Nagasato $K$, et al. Central motor conduction time (CCT) in patients with human T-lymphotropic virus Type I-associated myelopathy (HAM). In: Roman G, Vernant JC, Osame M, eds. HTLV-I and the Nervous System. New York: Alan R. Liss Inc., 1989: 239-244.

12. Rothwell JC, Thompson PD, Day BL, Boyd S, Marsden CD. Stimulation of the human motor cortex through the scalp. Exptl Physiol 1991; 76: 159-200.

13. Barker AT, Jalinous R, Freeston IL. Non-invasive stimulation of human motor cortex. Lancet 1985; 1: 1106-1107.

14. Ravnborg M, Liguori R, Christiansen P, Larsson H, Sørenson PS. The diagnostic reliability of magnetically evoked motor potentials in multiple sclerosis. Neurology 1992; 42: 1296-1301.

15. Barker AT, Freeston IL, Jalinous R, Jarratt JA. Clinical evaluation of conduction time measurements in central motor pathways using magnetic stimulation of human brain. Lancet 1986; I: $1325-1326$

16. Claus D, Waddy HM, Harding AE, Murray NMF, Thomas PK. Hereditary motor and sensory neuropathies and hereditary spastic paraplegia: a magnetic stimulation study. Ann Neurol 1990; 28: 43-49.

17. Osame M. Review of WHO Dagashima Meeting and Diagnostic Guidelines for HAM/TSP. $I n$ : Blattner WA, ed. Human Retrovirology: HTLV. New York: Raven Press. 1990: 192-195.

18. Abbruzzese G, Dall'Agata D, Morena M, et al. Electrical stimulation of the motor tracts in cervical spondylosis. J Neurol Neurosurg Psychiatry 1988; 51: 796-802.

19. Day BL, Dressler D, Maertens de Noordhout A, et al. Electric and magnetic stimulation of human motor cortex: surface EMG and single motor unit responses. J Physiol 1989; 412: 449-473.

20. Hess CW, Mills KR, Murray NMF. Magnetic stimulation of the human brain: facilitation of motor responses by voluntary contraction of ipsilateral and contralateral muscles with additional observations on an amputee. Neurosci Lett 1986; 71: 235-240.

21. Kimura J. Principles and pitfalls of nerve conduction studies. Ann Neurol 1984; 16: 415-429.

22. Ma DM, Liveson JA. Nerve Conduction Handbook, Philadelphia, USA, F.A. Davis Company, 1983: 362.

23. Wilkinson L. REGM: A multivariate general linear hypothesis program. Am Statistician 1980; 34: 182.

24. Wilkinson L. SYSTAT. SYSTAT, Inc., Evanston, IL., USA, 1987: 822.

25. Barker AT, Freeston IL, Jalinous R, Jarratt JA. Magnetic stimulation of the human brain and peripheral nervous system: an introduction and the results of an intitial clinical evaluation. Neurosurgery 1987; 20: 100-109.

26. Hess CW, Mills KR, Murray NMF. Responses in small hand muscles from magnetic stimulation of the human brait. J Physiol 1987; 388: 397-419.

27. Mills KR, Murray NMF. Hess CW. Magnetic and electrical transcranial brain stimulation: physiological mechanisms and clinical applications. Neurosurgery 1987; 20: 164-168.

28. Ingram DA, Thompson AJ, Swash M. Central motor conduction in multiple sclerosis: evaluation of abnormalities revealed by transcutaneous magnetic stimulation of the brain. J Neurol Neurosurg Psychiatry 1988; 51: 487-494.

29. Caramia MD, Pardal AM, Zarola F, Rossini PM. Electric versus magnetic transcranial stimulation of the brain in healthy humans: a comparative study of central motor tracts 'conductivity' and 'excitability'. Electroencephalogr Clin Neurophysiol 1989; 479: 98-104.

30. Cowan JMA, Rothwell JC, Dick JPR, et al. Abnormalities in central motor pathway conduction in multiple sclerosis. Lancet 1984; II: 304-307.

31. Berardelli A, Inghilleri M, Manfredi M, et al. Cortical and cervical stimulation after hemispheric infarction. J Neurol Neurosurg Psychiatry 1987; 50: 861-865.

32. Berardelli A, Inghilleri M, Cruccu G, et al. Stimulation of motor tracts in multiple sclerosis. J Neurol Neurosurg Psychiatry 1988; 51: 677-683. 
33. Ingram DA, Swash M. Central motor conduction is abnormal in motor neurone disease. J Neurol Neurosurg Psychiatry 1987; 50: 159-166.

34. Thompson PD, Day BL, Rothwell JC, et al. The interpretation of electromyographic responses to electrical stimulation of the motor cortex in deseases of the upper motor neurone. J Neurol Sci 1987; 80: 91-110.

35. Mayr N, Baumgartner C, Zeitlhofer J, Deecke L. The sensitivity of transcranial cortical magnetic stimulation in detecting pyramidal tract lesions in clinically definite multiple sclerosis. Neurology 1991; 41 : 566-569.
36. Arimura K, Arimura Y, Yonenaga Y, Rosales R, Osame M. Clinical electrophysiologic findings in patients with HTLV-I-associated myelopathy (HAM). In: Roman G, Vernant JC, Osame M, eds. HTLV-I and the Nervous System. New York: Alan R. Liss Inc., 1989: 245-250.

37. Masaru I, Higuchi I, Yoshimine K, et al. Pathological changes in skeletal muscle in HTLV-I-associated myelopathy. J Neurol Sci 1992; 110: 73-78.

38. Iwasaki Y. Pathology of chronic myelopathy associated with HTLV-I infection (HAM/TSP). J Neurol Sci 1990; 96: 103-123. 